\title{
Novedades de la Corte Interamericana de Derechos Humanos
}

James Vertiz Medina

\section{Corte IDH. Caso Lagos del Campo vs. Perú. Excepciones Preliminares, Fondo, Reparaciones y Costas. Sentencia de 31 de agosto de 2017. Serie C No. 340}

I. Hechos. El caso se relaciona con el despido arbitrario del Sr. Alfredo Lagos del Campo como consecuencia de manifestaciones realizadas siendo dirigente laboral en las que denunciara sobre actos de injerencia indebida de los empleadores en la representación sindical de los trabajadores, motivo por el cual fue despedido, medida que fue confirmada por los órganos judiciales del Perú.

II. Fondo. En este caso, el Tribunal de San José aborda la violación del derecho a la libertad de expresión desde el ámbito de las relaciones entre particulares en contextos laborales, resaltando que la libertad de expresión resulta una condición necesaria para el ejercicio de organizaciones de trabajadores, a fin de proteger sus derechos laborales, mejorar sus condiciones e intereses legítimos, puesto que sin este derecho dichas organizaciones carecerían de eficacia y razón de ser. Asimismo subrayó que en el ámbito laboral, la responsabilidad del Estado se puede generar bajo la premisa de que el derecho interno, tal como fue interpretado en última instancia por el órgano jurisdiccional nacional, habría convalidado una vulneración del derecho del recurrente, por lo que la sanción, en último término, deriva como resultado de la resolución del tribunal nacional, pudiendo ello acarrear un ilícito internacional.

Por otro lado, en esta histórica sentencia, la Corte declara por primera vez, y haciendo aplicación del principio iura novit 
curia, la violación del artículo 26 de la Convención Americana sobre Derechos Humanos, dando un decisivo paso hacia la justiciabilidad plena y directa de los derechos económicos, sociales, culturales y ambientales. En el caso, invocó su jurisprudencia sentada en el caso "Acevedo Buendía y otros vs. Perú" (2009), y como lo destaca el juez Ferre Mac Gregor, a través de una interpretación evolutiva y apartándose de su jurisprudencia tradicional, la Corte IDH le otorga un nuevo contenido normativo al artículo 26 del Pacto de San José, leído a la luz del artículo 29 del mismo instrumento.

En tal sentido, consideró el derecho a la estabilidad laboral como un derecho protegido por el artículo 26 de la Convención Americana, del cual se derivan, para las relaciones laborales en el ámbito privado, las siguientes obligaciones estatales: a) adoptar las medidas adecuadas para la debida regulación y fiscalización de dicho derecho; b) proteger al trabajador y trabajadora, a través de sus órganos competentes, contra el despido injustificado; c) en caso de despido injustificado, remediar la situación (ya sea, a través de la reinstalación o, en su caso, mediante la indemnización y otras prestaciones previstas en la legislación nacional). Por ende, d) el Estado debe disponer de mecanismos efectivos de reclamo frente a una situación de despido injustificado, a fin de garantizar el acceso a la justicia y la tutela judicial efectiva de tales derechos.

También en esta oportunidad la Corte Interamericana aplicó la protección del derecho de asociación en contextos laborales en relación con el artículo 26 del Pacto de San José.

III. Reparaciones. Entre otras medidas le ordenó al Estado de Perú pagar la cantidad fijada en la Sentencia por concepto de daño material, lo cual incluye el lucro cesante por los salarios dejados de percibir y su legítima pensión y beneficios sociales. Asimismo, otorgó un monto por concepto de daño inmaterial por las violaciones acreditadas. 


\section{Corte IDH. Caso Ortiz Hernández y otros vs. Venezuela. Fondo, Reparaciones y Costas. Sentencia de 22 de agosto de 2017. Serie C No. 338}

I. Hechos: El caso se relaciona con la muerte de Johan Alexis Ortiz Hernández, de 19 años de edad, en una instalación militar, siendo estudiante de la Escuela de Formación de Guardias Nacionales, como consecuencia de disparos de arma de fuego en el contexto de una práctica de fogueo realizada con balas reales, y en el que el Estado no dio una respuesta de manera adecuada ni oportuna, al no contar con personal médico especializado ni con una ambulancia que le permitiera recibir atención mientras era trasladado hasta un centro médico.

II. Fondo: El Tribunal Interamericano subrayó en este caso que, si bien la actividad militar conlleva en sí misma un riesgo por la naturaleza de sus funciones, el Estado se encuentra en la obligación de proteger la vida e integridad personal de los miembros de las fuerzas armadas en todos los aspectos de la vida militar, incluyendo los entrenamientos para afrontar situaciones de guerra o conflicto, así como el mantenimiento de la disciplina militar, entre otros. En esta línea, la Corte consideró que recae sobre el Estado el deber de adoptar medidas preventivas de diversa índole, entre ellas de carácter administrativo o legislativo, a fin de reducir el nivel de riesgo al que se enfrentan los miembros de las fuerzas armadas en el marco de la vida militar.

En el asunto, el reproche y la consecuente atribución de responsabilidad estuvo determinada por la ausencia de regulación apropiada en la ejecución de la práctica o entrenamiento militar en lo relativo a la utilización de balas de fogueo y/o balas reales, la que está permitida en tanto la misma no genere un riesgo excesivo sobre la vida e integridad de las personas; por a la falta de cumplimiento de las medidas de seguridad para proteger el derecho a la integridad personal y a la vida, incluyendo la previsión y provisión de atención médica oportuna y adecuada; 
y asimismo por lo atinente al carácter arbitrario de la muerte y la plausibilidad de las -4- hipótesis planteadas sobre cómo sucedieron los hechos. Por esto, y atento el reconocimiento de responsabilidad estatal, la Corte decidió que se violaron los artículos 4.1 y 5.1 de la Convención Americana, en relación con el artículo 1.1 de la misma.

III. Reparaciones: La Corte estableció entre otras medidas de reparación, y para recuperar la memoria de la víctima, que se designar con el nombre de Johan Alexis Ortiz Hernández una promoción de egresados de la Escuela de Formación de Guardias Nacionales; y que de acuerdo a la naturaleza y finalidad de cada ejercicio en el ámbito de la instrucción militar de los estudiantes de la Escuela de Formación de Guardias Nacionales, establecer de forma expresa el tipo de municiones a utilizarse y, en su caso, justificar de forma estricta la necesidad militar de utilizar balas reales en un ejercicio en concreto.

\section{Corte IDH. Caso Favela Nova Brasilia vs. Brasil.} Excepciones Preliminares, Fondo, Reparaciones y Costas. Sentencia de 16 de febrero de 2017. Serie C No. 333

I. Hechos: El caso se relaciona con la falta de investigación y sanción de los responsables por las ejecuciones extrajudiciales de 26 personas, así como por la comisión de actos de violencia sexual tres mujeres, dos de ellas niñas, todas en el marco de dos redadas policiales efectuadas por la Policía Civil de Río de Janeiro en 1994 y 1995 en la Favela Nova Brasilia. Las autoridades policiales justificaron dichas muertes mediante el levantamiento de actas de resistencia al arresto.

II. Fondo: Al tratar sobre el fondo del caso, en primer lugar, elabora estándares sobre independencia de los órganos investigadores en casos de muerte derivada de intervención policial. En tal sentido subrayo que, el elemento esencial de una investigación penal sobre una muerte derivada de intervención 
policial es la garantía de que el órgano investigador sea independiente de los funcionarios involucrados en el incidente. Esa independencia implica la ausencia de relación institucional o jerárquica, así como su independencia en la práctica. En ese sentido, en los supuestos de presuntos delitos graves en que prima facie aparezca personal policial como posible imputado, la investigación debe estar a cargo de un órgano independiente y diferente de la fuerza policial involucrada en el incidente, tales como una autoridad judicial o el Ministerio Público, asistido por personal policial, técnicos de criminalística y administrativos, ajenos al cuerpo de seguridad al que pertenezca el posible imputado o imputados.

Luego se refiere a los estándares relativos a debida diligencia y plazo razonable en casos de alegada violencia sexual. Allí la Corte destaca que, siguiendo la línea de la jurisprudencia internacional y tomando en cuenta lo dispuesto en la Convención de Belém do Pará, ha considerado que la violencia sexual se configura con acciones de naturaleza sexual que se cometen contra una persona sin su consentimiento, que además de comprender la invasión física del cuerpo humano, pueden incluir actos que no involucren penetración o incluso contacto físico alguno. Asimismo, de conformidad con el criterio jurisprudencial y normativo que impera tanto en el ámbito del Derecho Penal Internacional como en el Derecho Penal comparado, considera que la violación sexual no implica necesariamente una relación sexual sin consentimiento, por vía vaginal, como se consideró tradicionalmente. Por violación sexual también debe entenderse actos de penetración vaginal o anal, sin consentimiento de la víctima, mediante la utilización de otras partes del cuerpo del agresor u objetos, así como la penetración bucal mediante el miembro viril.

En el caso la Corte también reitera su jurisprudencia de que la violación sexual es una forma de tortura, y que en casos de violencia contra la mujer, ciertos instrumentos internacionales resultan útiles para precisar y dar contenido a la obligación estatal reforzada de investigarlos con la debida diligencia. 
Entre otros, en una investigación penal por violencia sexual es necesario que: i) la declaración de la víctima se realice en un ambiente cómodo y seguro, que le brinde privacidad y confianza; ii) la declaración de la víctima se registre de forma tal que se evite o limite la necesidad de su repetición; iii) se brinde atención médica, sanitaria y psicológica a la víctima, tanto de emergencia como de forma continuada si así se requiere, mediante un protocolo de atención cuyo objetivo sea reducir las consecuencias de la violación; iv) se realice inmediatamente un examen médico y psicológico completo y detallado por personal idóneo y capacitado, en lo posible del sexo que la víctima indique, ofreciéndole que sea acompañada por alguien de su confianza si así lo desea; v) se documenten y coordinen los actos investigativos y se maneje diligentemente la prueba, tomando muestras suficientes, realizando estudios para determinar la posible autoría del hecho, asegurando otras pruebas como la ropa de la víctima, investigando de forma inmediata el lugar de los hechos y garantizando la correcta cadena de custodia; vi) se brinde acceso a asistencia jurídica gratuita a la víctima durante todas las etapas del proceso, y vii) se brinde atención médica, sanitaria y psicológica a la víctima, tanto de emergencia como de forma continuada si así se requiere, mediante un protocolo de atención cuyo objetivo sea reducir las consecuencias de la violación. Asimismo, en casos de supuestos actos de violencia contra la mujer, la investigación penal debe incluir una perspectiva de género y realizarse por funcionarios capacitados en casos similares y en atención a víctimas de discriminación y violencia por razón de género.

III. Reparaciones: En esta ocasión, la Corte ordenó entre otras medidas reparatorias la de publicar anualmente un informe oficial con los datos relativos a las muertes producidas durante operativos de la policía en todos los estados del país y con información actualizada anualmente sobre las investigaciones realizadas respecto a cada incidente resultante en la muerte de un civil o de un policía; la de establecer los mecanismos normativos necesarios para que en supuestos de presuntas muertes, 
tortura o violencia sexual derivadas de intervención policial, en que prima facie aparezca personal policial como posible imputado, desde la notitia criminis se encargue la investigación a un órgano independiente y diferente de la fuerza pública involucrada en el incidente, tales como una autoridad judicial o el Ministerio Público, asistido por personal policial, técnico criminalístico y administrativo ajeno al cuerpo de seguridad al que pertenezca el posible imputado o imputados; y la de adoptar las medidas necesarias para que el Estado de Río de Janeiro establezca metas y políticas de reducción de la letalidad y la violencia policial.

\section{Corte IDH. Caso Zegarra Marín vs. Perú. Excepciones Preliminares, Fondo, Reparaciones y Costas. Sentencia de 15 de febrero de 2017. Serie C No. 331}

I. Hechos: El caso se relaciona con la violación al principio de presunción de inocencia y al deber de motivación de las sentencias en perjuicio del señor Zegarra Marín, a cargo de la Subdirección de Pasaportes de la Dirección de Migraciones y Naturalización del Perú, quien fue condenado por la supuesta expedición de pasaportes tramitados en forma irregular, en base a las declaraciones de sus coimputados, como único elemento de prueba en la causa.

II. Fondo: En este caso la Corte construye y reafirma sus estándares en materia del alcance del principio de presunción de inocencia; del valor probatorio de co-imputados; sobre la carga probatoria y la inversión de la misma; y sobre el deber de motivar.

Respecto del valor probatorio de las declaraciones de coimputados, la Corte resaltó que las declaraciones de los coacusados revisten valor indiciario $\mathrm{y}$, por consiguiente, forman parte de la prueba indirecta o indiciaria, debiendo valorar sus contenidos conforme a los principios de la sana crítica; es decir, que para alcanzar una condena es necesario que sean varios 
los indicios y que, entre ellos, sean serios y precisos, así como concordantes. El coimputado no tiene el deber de presentar declaraciones dado que realiza un acto sustancial de defensa, a diferencia del testigo.

En relación a la carga probatoria y la inversión de la misma, la Corte reiteró que la demostración fehaciente de la culpabilidad constituye un requisito indispensable para la sanción penal, de modo que la carga de la prueba recae en la parte acusadora y no en el acusado, y que el acusado no debe demostrar que no ha cometido el delito que se le atribuye, ya que el onus probandi corresponde a quien acusa y cualquier duda debe ser usada en beneficio del acusado. En consecuencia, al presumir la culpabilidad del inculpado, requiriendo que sea éste quien demuestre su inculpabilidad, se vulnera el derecho a la presunción de inocencia. Asimismo, destacó que la carga de la prueba en procesos penales se sustenta en el órgano del Estado, por lo que no existe la obligación del acusado de acreditar su inocencia ni de aportar pruebas de descargo. Es decir, la posibilidad de aportar contraprueba es un derecho de la defensa para invalidar la hipótesis acusatoria, contradiciéndola mediante contrapruebas o pruebas de descargo compatibles con hipótesis alternativas (contra-hipótesis), que a su vez la acusación tiene la carga de invalidar.

Sobre el deber de motivar, la Corte subraya la relevancia de la motivación, a fin de garantizar el principio de presunción de inocencia, principalmente en una sentencia condenatoria, la cual debe expresar la suficiencia de prueba de cargo para confirmar la hipótesis acusatoria; la observancia de las reglas de la sana crítica en la apreciación de la prueba, incluidas aquellas que pudieran generar duda de la responsabilidad penal; y el juicio final que deriva de esta valoración. En su caso, debe reflejar las razones por las que fue posible obtener convicción sobre la imputación y la responsabilidad penal, así como la apreciación de las pruebas para desvirtuar cualquier hipótesis de inocencia, y solo así poder confirmar o refutar la hipótesis acusatoria. Lo anterior, permitiría desvirtuar la presunción de 
inocencia y determinar la responsabilidad penal más allá de toda duda razonable. Ante la duda, la presunción de inocencia y el principio in dubio pro reo, operan como criterio decisorio al momento de emitir el fallo.

III. Reparaciones: la Corte determinó entre otras, como medida de reparación integral, que la sentencia de condena que fue emitida en el proceso penal en contra de Agustín Zegarra Marín carece de efectos jurídicos en lo que respecta a la víctima en el presente caso y, por lo tanto, dispone que el Estado debe adoptar todas las medidas necesarias para dejar sin efecto las consecuencias que de ella se derivan así como los antecedentes judiciales o administrativos, penales o policiales, que existan en su contra a raíz de dicho proceso, otorgándole a Perú el plazo de un año para cumplir con la misma. 